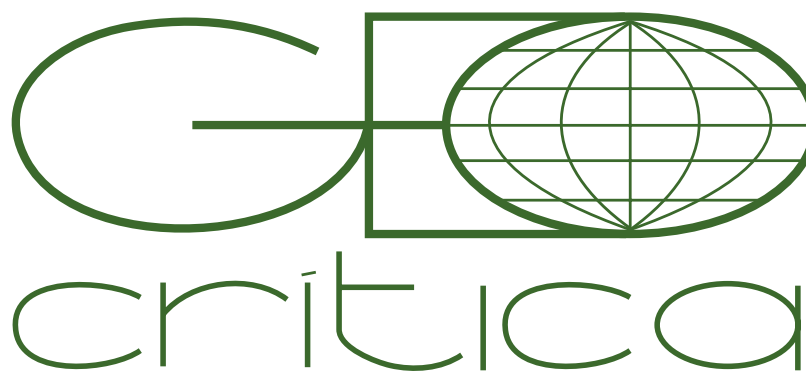

\section{Scripta Nova}

Revista Electrónica de Geografía y Ciencias Sociales Universitat de Barcelona

\title{
PRÁTICA ARGUMENTATIVA NO ENSINO DE GEOGRAFIA: UM ESTUDO A PARTIR DO CONCEITO DE TERRITÓRIO
}

\author{
Eden Correia Carli \\ Universidade Federal de São Paulo \\ carlieden@yahoo.com.br \\ Jerusa Vilhena de Moraes \\ Universidade Federal de São Paulo \\ jevilhena@yahoo.com.br
}

Recibido: 9 de noviembre de 2017. Devuelto para correcciones: 28 de enero de 2018. Aceptado 14 de marzo de 2018

\section{Pratica argumentativa no ensino de geografia: um estudo a partir do con- ceito de território (Resumo)}

A proposta desse estudo foi de investigar "quais são" e "como são" desenvolvidos os argumentos científicos construídos pelos alunos dos anos finais do ensino fundamental de três escolas públicas do município de São Paulo. Como ferramenta de coleta de dados nos utilizamos de um questionário investigativo tipo teste de conhecimento. As discussões que envolvem essa investigação, analisam a qualidade do argumento dos estudantes no contato com a teoria científica apresentada através do padrão de argumento desenvolvido pelo filósofo inglês Stephen Toulmin e outras ferramentas de refinamento das suas categorias. São preocupações também a esta pesquisa contextualizar a análise do papel da moral e da ética na tomada de decisões contidos nos argumentos coletados. Os resultados demonstram as potencialidades do campo da argumentação científica em propiciar novos passos para as pesquisas e prática em sala de aula na disciplina de Geografia.

Palavras-chave: Ensino de Geografia, Argumentação Científica, Território, cidadania.

\section{Argumentative practice in geography education: a study from the con- cept of territory (Abstract)}

The aim of this study was to investigate "what are" and "how are" developed the scientific arguments constructed by the students of the final years of elementary school of three public schools in the city of São Paulo. As research tool, we were use a kind of knowledge test questionnaire. The discussions that involve this investigation analyse the quality of the students' argument in the contact with the scientific theory presented through the pattern of argument developed by the English philosopher Stephen Toulmin and other tools refinement of yours categories. They are also concerns to this research contextualize the analysis of the role of morality and ethics in the decision-making contained in the arguments collected. The results demonstrate the potential of the field of scientific argumentation in providing new steps for research and classroom practice in the discipline of Geography.

Keywords: Geography teaching, scientific argumentation, Territory, citizenship. 
Na apresentação desta pesquisa na área de ensino de geografia nos utilizamos do termo ciências e das pesquisas em ensino de ciência por compreendermos, que o campo de pesquisa em Geografia se insere e possui dinâmicas racionais da atividade científica. Dentre elas incluímos a resolução de problemas, o desenvolvimento de metodologias, a produção de teorias e explicações e as dinâmicas sociais de divulgação e produção de conhecimento ${ }^{1}$.

Tais dinâmicas científicas podem não ser suficientes para o esclarecimento desta aproximação, principalmente se ignorarmos que as epistemologias no campo das ciências se apresentam de formas muito diversa. Reconhecemos como não habitual esse tratamento para a Geografia, porém nessa proposta de aproximação do campo de pesquisa do ensino de ciência e do ensino de Geografia achamos pertinente incutirmos os potenciais avanços que está aproximação pode provocar.

$\mathrm{O}$ alcance de tal potencial pode ser medido na pesquisa de Moraes ${ }^{2}$ que investigou a articulação entre a aprendizagem baseada em resolução de problemas (Problem Based Learning) ao ensino de Geografia como proposta de Alfabetização Científica. Dentre suas contribuições a proposta de analisar ações voltadas para a prática de ensino em sala de aula demonstraram que ao incorporar as dimensões da cultura científica não apenas existe uma contribuição para a cidadania, mas também para uma melhor apropriação de conceitos da Geografia Escolar.

Outra aproximação está na proposta de Castellar em discutir as contribuições de Bachelard ${ }^{3}$ e suas ideias sobre erros conceituais e obstáculos epistemológicos para o ensino de Geografia. Dentre suas contribuições destacamos aqui a defesa de que a aprendizagem conceitual tenha um status de suporte para as metodologias em Geografia, aportadas na promoção de raciocínio motivados para dar significado ao mundo a partir da relação entre o pensamento científico e as concepções cotidianas desses estudantes ${ }^{4}$.

Refletindo nossa compreensão de que a Geografia que se ensina é uma ciência buscou-se na pesquisa que apresentaremos a aproximação com o campo de pesquisas em Argumentação Científica5.

As discussões que envolvem este campo de pesquisas apresentam como reflexão para a aprendizagem a importância do discurso na promoção do conhecimento científico partindo do pressuposto de que aprender ciências é também aprender a ler, falar e escrever sobre ciências e sua construção de explicações, teoria e evidências, faceta está próxima aos objetivos de alfabetização científica em Geografia.

Estudos nesse campo com aplicações em Soft Science, não são incomuns. O estudo de Pontecorvo \& Girardet ${ }^{6}$, por exemplo, desenvolveu uma investigação para o

\footnotetext{
1 Moraes, 2010

2 Moraes, 2010.

3 Bachelard, 1996.

4 Castellar e Souza, 2016.

5 Está investigação faz parte das discussões do grupo de pesquisa "Alfabetização científica e as metodologias ativas no ensino de Geografia", sediado na Universidade Federal de São Paulo.

6 Pontecorvo e Girardet,1993.
} 
ensino de história. Este estudo repercute no campo de pesquisas em argumentação científica, sendo citado em muitos dos trabalhos que consultamos, mesmo quando estão discutindo temas ou problemas das ciências naturais.

No campo da Geografia uma única pesquisa ${ }^{7}$ que tivemos acesso utilizou-se da argumentação científica como ferramenta para analisar as sequências argumentativas nas respostas dos alunos frente a problemas da chamada "área física" da disciplina. Sendo que, ao término dessa publicação as autoras indicam que outros estudos estão sendo desenvolvidos na Potsdam University (Alemanha) ${ }^{8}$.

O fato de outras áreas de conhecimento, inclusive a Geografia, estarem preocupadas em verificar os potenciais desse campo exemplificam nosso interesse, revivificando nossa preocupação em refletir sobre ações voltadas para a promoção da Alfabetização Científica.

O estudo que apresentaremos buscou fornecer subsídios para a compreensão da aquisição do discurso científica pelos alunos: Diante desse objetivo analisamos os argumentos escritos produzidos pelos alunos das séries finais do ensino fundamental II de três escolas públicas da cidade de São Paulo ( $9^{\circ}$ anos). A atividade apresentava aos estudantes um cenário sociocientífico que demonstrava uma pesquisa, seguido por um questionário tipo teste de conhecimento ${ }^{9}$, instrumento que utilizamos para a coleta de dados.

A perspectiva que adotamos para o conceito de território nessa atividade está implicitamente relacionada a proposta de Haesbaert de uma abordagem relacional - que busca compreender o território como elemento constituinte da sociedade, a partir das múltiplas relações sociais e culturais e a necessidade de entender a vivência das pessoas nestes territórios, inclusive suas subjetividades e de Souza que ressalta a necessidade de compreendermos que a materialidade dos processos de formação do território exige compreendermos as complexas territorialidades que o cotidiano expressa ${ }^{10}$.

Seguimos como metodologia de análise dos argumentos produzidos pelos estudantes, primeiramente, a identificação dos elementos argumentativos construídos pelos estudantes e o exame através das categorias do padrão de argumento de Toulmin (TAP - Toulmin Arguments Pattern) - o uso de dados (D), Justificações (J), a Fundamentação (F) para definição da conclusão (C) e a capacidade de refutação (R). Uma segunda etapa de análise propôs a correspondência dos argumentos válidos: a) sobre a suficiência dos dados, b) a relação entre os dados e garantia (fundamentação teórica e justificação) para o estabelecimento de conclusões e, também, c) o diagnóstico da validade científica das informações, seguidos por uma distinção de acordo com os níveis de justificação ${ }^{11}$. Foram preocupações também a esta pesquisa contextualizar a análise do papel da moral e da ética na tomada de decisões contidos nos argumentos coletados ${ }^{12}$, nossa terceira etapa de análise.

7 Budke, Schiefele Uhlenwinkel, 2010.

8 Após o término desta pesquisa tivemos acesso a mais três trabalhos sobre o campo da argumentação científica pensado para o ensino de geografia, sendo estes: Morgan, 2006; Johnson, 2005; Roberts, 2013, cap. 8.

9 Metodologia descrita por Lima, 2008.

10 Haesbaert, 2011 e Souza, 2000.

11 Conforme a proposta do estudo de Lima, 2008.

12 Conforme apresentado por Zeidler \& Sadler, 2007. 
Duas escolas da rede municipal e uma escola da rede estadual de ensino, na cidade de São Paulo, foram selecionadas adotando-se como critérios: a proximidade com realidades assinaladas pelo questionário tipo teste de conhecimento aplicado e a presença de alunos da série final do Ensino Fundamental II no Brasil ( $9^{\circ}$ anos). A escolha da série final do ensino fundamental está fundamentada na necessidade de compreendermos as dificuldades encontradas por estes estudantes, porque elas persistem e em que momentos existem obstáculos ao avanço conceitual destes. Todos os 47 alunos que participaram da pesquisa se voluntariaram após o convite feito pelo pesquisador e o incentivo de professores e coordenadores das escolas que participaram.

\section{Pesquisa, ensino e aprendizagem em Argumentação Científica}

Um referencial de análise importante para o desenvolvimento do campo de pesquisa em argumentação científica é o trazido pelo filósofo inglês Stephen Toulmin ${ }^{13}$ (1922-2009), que preocupado em responder questões como: "Quais as razões que temos para a alegação de conhecimento que fazemos? Estão as razões em que baseamos nossas alegações de conhecimento sempre, de fato, à altura de um padrão? ", conduziu seus trabalhos a proposta de um modelo para a análise de argumentos (TAP - Toulmin's Argument Pattern).

Para isso, o autor se dedica a análise das condições em que estes argumentos são produzidos, seja sobre problemas cotidianos, problemas científicos e/ou problemas jurídicos.

Alguns exemplos para compreendermos como este padrão se situa em cada uma dessas condições são pensarmos que elementos da argumentação apresentamos na experiência do cotidiano para defender as possibilidades de um time de futebol ganhar um campeonato, ou ainda, que elementos da argumentação são acionados por cientistas para defender a tese das mudanças climáticas causadas pelo homem, ou mesmo, que justificações e provas são utilizadas por um juiz para argumentar sobre sua decisão.

Para que possamos aumentar a força de persuasão de um argumento ${ }^{14}$ segundo a TAP (figura 1), são necessárias categorias analíticas que forneçam garantias para nossas conclusões. Isto inclui o uso de dados (D), a capacidade de Justificação (J) e de Fundamentação (F) que nos permita compreender o raciocínio proposto, a refutação (R), que nos possibilita compreender as contestações, limites e/ou condições de exceção das conclusões tomadas, e ainda, os qualificadores modais (Q), normalmente um advérbio que dá aval a garantia (como possível/impossível, provável/ improvável, etc.) para a definição da conclusão (C).

13 Toulmin, 2001.

14 Erduran, Simon \& Osbourne, 2004. 


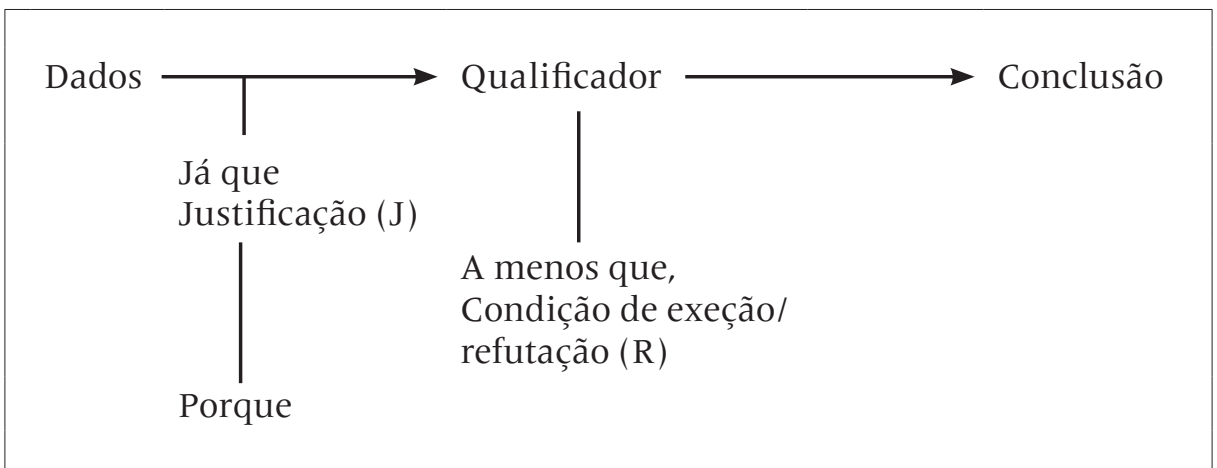

Figura 1: Modelo do padrão de argumento de Toulmin (TAP)

A apresentação de um padrão do argumento propiciou o desenvolvimento de hipóteses de trabalho de diferentes estudos que se debruçaram sobre cada elemento e a interação entre estes buscando compreender como os estudantes e professores oferecem dados, justificações e fundamentação para seus argumentos, como podemos desenvolver a capacidade crítica dos estudantes à partir do desenvolvimento da refutação, como questões sociocientíficas interferem na tomada de decisão dos estudantes, como analisar evoluções epistemológicas nos argumentos de estudantes e cientistas, etc.

Como uma controvérsia sobre a produção do discurso em sala de aula se desenvolveram teses neste campo de pesquisas em que o argumento é visto ora como expressão do raciocínio ou como contextos sociais dialógico, ambas as perspectivas engendram formas de como compreendemos o processo de construção de conhecimento e as dimensões de como estamos examinando este processo. Neste aspecto, concordamos com Jiménez-Aleixandre \& Brocos que consideram que: “(...) argumento tem tanto um significado individual, de articulação de um ponto de vista, como social, de debate"15.

Isso nos possibilita compreender que existem diferentes perspectivas cognitivas implícitas a nossa capacidade de comunicar um conhecimento científico e que, portanto, quando mencionamos a argumentação científica como uma habilidade que permite ao estudante comunicar suas ideias de forma mais significativa, nos interessa provocar a reflexão sobre as narrativas que estão se desenvolvendo em sala de aula.

Como implicações em sala de aula compreendemos que a argumentação como estratégia de ensino pode nos provocar a pensar como construir um discurso científico, o que coloca a necessidade de que os alunos "questionem, expliquem, levantem hipóteses, chequem-nas, considerem evidências e informações"16, elementos que configuram a cultura científica.

15 Jiménez-Aleixandre \& Brocos, 2015, p. 145. Como elementos que sustentam a afirmação de Jiménez-Aleixandre \& Brocos (2015) estas lembram pesquisas que apontam que processos internos individuais também podem ser considerados como argumentos, mas que é preciso lembrar que a cadeia interna de raciocínios também encontra relações com os diálogos externos.

16 Sasseron, 2008, p. 46. 
Sobre a inserção da argumentação científica em políticas internacionais (como, o exame PISA e sua inserção em currículos nacionais ${ }^{17}$ ) Erduran \& Jiménez-Alexandre $^{18}$ observaram a presença de dois objetivos principais descritos: um primeiro se refere a ideia de uma ciência para todos, que busca formar cidadãos para a compreensão das relações sociais, econômicas, culturais e as condições políticas do argumento cientifico. O segundo, está relacionado a ciência para a perspectiva cientifica, de problematizar os processos e os contextos da produção científica para formar novos cientistas.

Todos estes panoramas do campo de pesquisas em argumentação científica têm como preocupação entender os discursos científicos promovidos na escola, colocando em foco não apenas a aprendizagem do conceito (a teoria), mas a ampliação das preocupações sobre o processo de aprendizagem para como nós conhecemos (metodologia científica) e porque nós acreditamos que conhecemos (epistemologia da ciência $)^{19}$, sendo que concebemos estas contribuições como um meio de explorar o discurso da ciência geográfica no processo de ensino aprendizagem.

Tais contribuições somados a todas as dimensões exploradas nessa seção fundamentam a produção de nosso material de coleta de dados e a análise dos argumentos escritos que coletamos dos estudantes que aceitaram participar da pesquisa.

\section{Prática Argumentativa no Ensino de Geografia com estudantes do final do ciclo do ensino fundamental II, a partir do conceito de Terri- tório}

Como ferramenta de coleta de dados foi feito uso de um questionário investigativo tipo teste de conhecimento ${ }^{20}$ que levou em conta os objetivos contidos na proposta de pesquisa de identificação dos argumentos científicos desenvolvido pelos estudantes.

A produção do instrumento de coleta de dados foi feita a partir dos critérios para organização dos instrumentos de análises (Figura 2). Dentre as implicações que repercutiram neste instrumento recuperamos como procedimentos interpretativos para a demanda da construção de um cenário sociocientífico, as propostas de Souza e Haesbaert ${ }^{21}$ acerca do conceito de território.

Outro fator elencado como prioridade para a produção do instrumento de análise consistia em que o conteúdo do questionário tipo teste de conhecimento deveria

17 Reconhecemos que em ambas as políticas internacionais não se aborda o campo da Geografia, mas como havíamos apontado em nossa introdução, são as facetas de contato que estamos explorando neste artigo, afim de diagnosticar as potencialidades desse campo de pesquisa para a geografia. O Programme for International Student Assessment (PISA), por exemplo, que é organizado pela OCDE constitui-se como uma importante avaliação internacional em ciências que em sua matriz de desenvolvimento apresenta como habilidades a serem avaliadas a capacidade de coordenar evidências e a argumentação dos estudantes (Jimenéz-Aleixandre e Erduran, 2007).

18 Erduran \& Jiménez-Alexandre, 2007

19 Duschl, 2007.

20 Ver questionário em anexo.

21 Souza, 2000 e Haesbaert, 2011. 
repercutir questões relacionadas a um problema próximo ou vivenciado por estes estudantes nestes territórios. Como uma atividade reflexiva implicada a formação para cidadania ${ }^{22}$, a expectativa gerada com essa proposta foi que esta pudesse fornecer indícios mais substanciais sobre a construção do argumento desses estudantes, principalmente acerca dos elementos da experiência da juventude em multiterritorialidades.

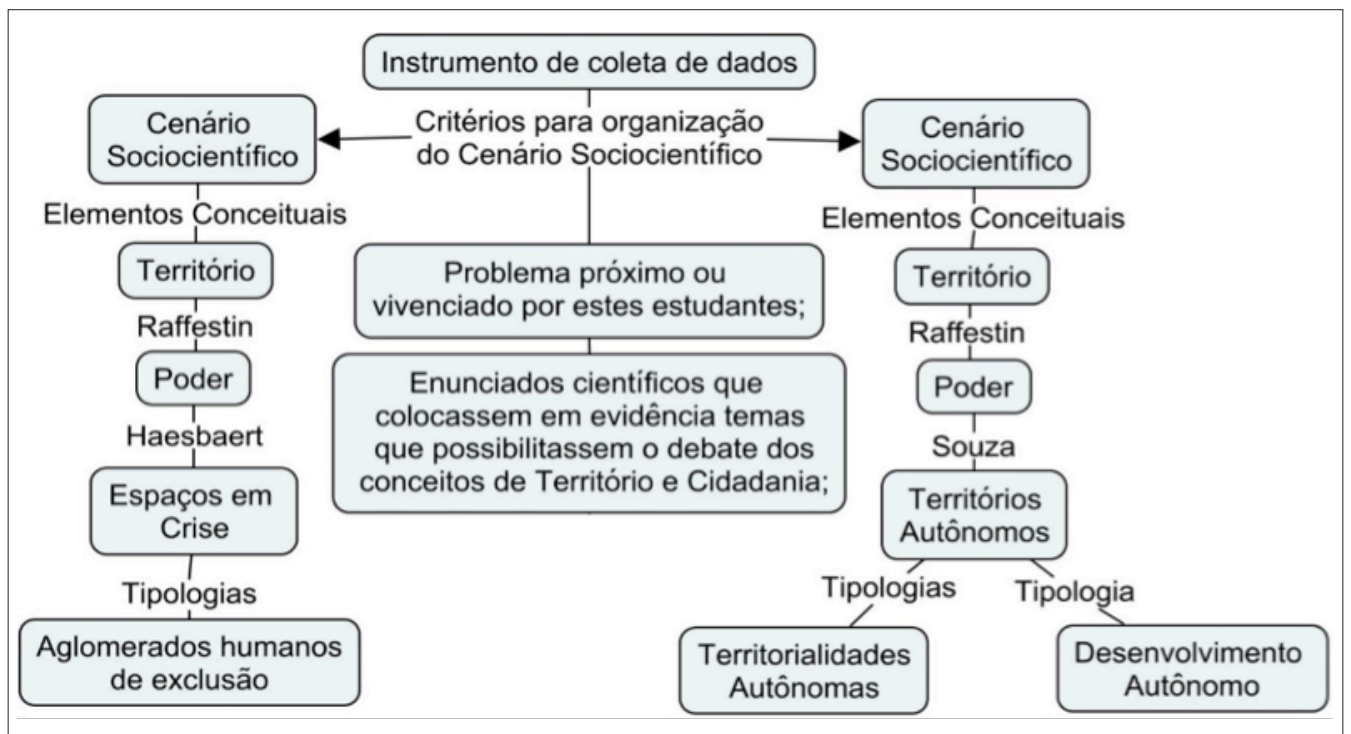

Figura 2. Mapa conceitual sobre os critérios para produção do instrumento de coleta de dados

Elaborado por: Carli, Eden C.

Inseridos nestas preocupações, inicialmente buscamos pesquisas científicas que colocassem em evidência temas que possibilitassem o debate de conceitos que já destacamos. Dois estudos repercutiram de forma positiva para os critérios levan$\operatorname{tados}^{23}$.

Os estudos trazem preocupações com áreas informais de habitações; as chamadas favelas e/ou comunidades; ou ainda, conceitualmente definido para o nosso diagnóstico sobre território como aglomerados humanos de exclusão que se configuram por territorializações precárias, espaços estes presentes na realidade das cidades brasileiras.

A partir da problematização elaborada pelas pesquisas de Torres \& Marques e Bon Junior, organizamos o cenário sociocientífico em vista de apresentá-lo com uma linguagem mais

22 As referências apresentadas são importantes para fundamentarmos as relações aqui pretendidas entre a aprendizagem em Geografia e a formação para cidadania. Visamos com estas apontarmos para perspectivas interpretativas que orientem o ensino de Geografia no campo das ciências para uma reflexão mais crítica, que seja compreendido como um processo de apropriação da cultura científica e que, em vista de uma formação para a cidadania deve estar articulada com sua forma de argumentar, com seus dilemas sociocientíficos (Kolstø \& Ratcliffe, 2007) e a necessidade de articular o pensar e o conhecimento, conjuntamente com o questionar-se sobre o outro (Arendt 2000 e 2015), refletindo as implicações da cultura científica e do desenvolvimento técnico.

23 Torres \& Marques, 2002 e Bon Junior, 2005. 
própria para os estudantes. Por isso, ao invés de apresentarmos os artigos científicos, o conteúdo do questionário tem como principal característica ser o diário de um pesquisador do Instituto de Geografia (Anexo 1).

Para a apresentação dos resultados a próxima seção segue organizada em dois seguimentos. O primeiro foca sobre a análise da qualidade da argumentação dos estudantes e na capacidade de identificação de evidências empíricas e de explicações causais. O segundo apresenta a análise da tomada de decisão dos estudantes frente à diálogos de questões sociocientíficas, em que foram examinados o julgamento do mérito e os fundamentos utilizados pelos estudantes sobre as pesquisas.

\section{Análise da qualidade dos argumentos dos estudantes}

Dentre as respostas as alternativas apresentadas na primeira parte da questão 1 do questionário os alunos concordaram que "Sim" o cientista tinha condições de afirmar que existem dificuldades em medir o tamanho da população residente em favelas na cidade de São Paulo (46 alunos), apenas ( 1 aluno) registrou que "Tinha dúvidas" e nenhum estudante marcou a alternativa "Não".

Apesar dos dados demonstrarem a concordância de grande parte dos estudantes com a afirmação do cientista, a correlação entre este dado e as justificações apresentaram variedades de conteúdos e operações lógicas que não necessariamente fizeram uso de informações cientificamente válidas.

Numa primeira etapa de análise dos argumentos dos estudantes, focamos na identificação dos elementos argumentativos identificando o padrão de argumentação desenvolvido para cada resposta. Classificamos o uso de dados (D), a conclusão (C) apresentada, a presença da fundamentação $(\mathrm{F})$ e justificação $(\mathrm{J})$ e a refutação $(\mathrm{R})$. A partir desse seguimento de análises foram identificadas as seguintes sequências argumentativas:

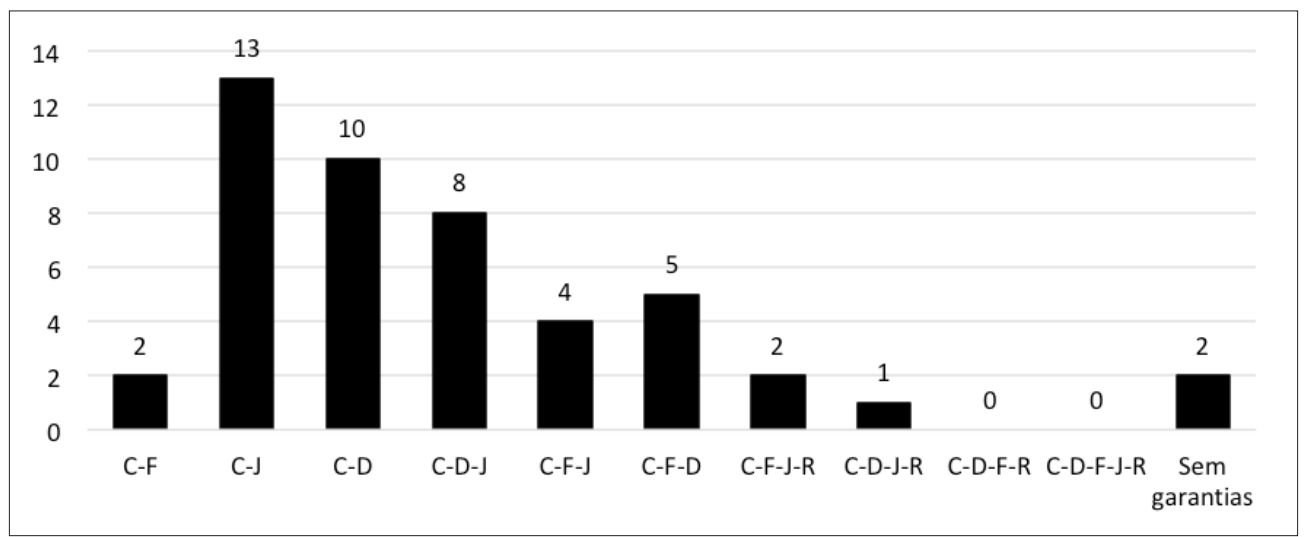

Figura 3: Sequências argumentativas identificadas nas respostas à questão Elaborado por Carli, Eden C.

Os dados da figura 3 descrevem que as sequências nos textos escritos mais utilizadas pelos estudantes foram as sequências duplas ( 25 estudantes), as sequências argumentativas triplas mais completas em termos de argumentação, foram encontradas nos textos escritos de 17 estudantes, incrementando o nível de complexidade 
encontramos o seguimento quádruplo para argumentação nas sequências Fundamentação, Justificações e Refutação (2 estudantes) e Dados, Justificações e Refutação ( 1 estudantes). Em nenhuma resposta encontramos um nível de argumentação que se utilizasse de todas as 5 estruturas (Conclusão, Dados, Fundamentação, Justificação e Refutação) na mesma resposta.

A seguir apresentaremos exemplos para demonstrar a forma de identificação das sequências argumentativas apresentadas no gráfico 1. Iniciaremos pelas sequências duplas:

\footnotetext{
"Sim, porque as duas instituições que mediram o tamanho da população nas favelas deram resultados diferentes" (a25,eC24).

"Porque havia confusões na prefeitura e no IBGE, e isso causou dificuldade para o pesquisador." (a l l,eA,Q1,PI)

"Sim, pode afirmar, pois o pesquisador teve que fazer todo um cálculo que tinham várias etapas e, que não são simples." (al 7, eB)
}

A primeira afirmação (a25, eC) foi identificada como um argumento que se utiliza de dados (D) ("porque as duas instituições que mediram o tamanho da população nas favelas deram resultados diferentes") para apoiar a Conclusão (C) ("Sim").

A segunda afirmação (all,eA) foi identificada como um argumento que se utiliza de justificações ( J) ("Porque havia confusões na prefeitura e no IBGE, e isso causou dificuldade para o pesquisador") como uma forma de apoio para a conclusão (“Sim").

A terceira afirmação desenvolvida (a 17, eB) foi identificada como um argumento que se utiliza de uma conclusão (C) ("Sim, pode afirmar") seguido pelo uso de uma garantia que busca na fundamentação (F) do cenário sociocientífico o apoio para validar a afirmação ("pois o pesquisador teve que fazer todo um cálculo que tinham várias etapas e, que não são simples"). O apoio do estudante a autoridade do pesquisador é outro elemento neste argumento que chama a atenção.

A falta de desenvolvimento de outras garantias, como os dados para demonstrar como esta metodologia ajudou o pesquisador, são elementos que corroboram a tese, que também pode ser aplicada a todas as sequências duplas identificadas, de que este argumento tem pouca força de persuasão. Para alguns autores, como Sardá Jorge \& Sanmartí Puig ${ }^{25}$ estes argumentos não seriam considerados com validade formal, por apresentarem menos do que dois elementos argumentativos, opinião está compartilhada por Lima ${ }^{26}$ em seu estudo.

Os seguimentos triplos que identificamos (C-D-J, C-F-J e C-F-D) podem ser classificados como sequências argumentativas mais completas, por fazerem uso de mais de uma garantia para apoiar a afirmação. Os exemplos que se seguem buscam ilustrar o padrão utilizado para identificação desses seguimentos:

24 Atribuímos a notação Ey (sendo Y o número que identifica a escola) e a notação Ax (Sendo X o número do aluno que respondeu).

25 Sardá Jorge \& Sanmartí Puig, 2000.

26 Lima, 2008. 
"Porque primeiro ele teve que comparar as áreas nos locais em que haviam confusões entre a prefeitura e o IBGE. Ele teve que pesquisar a densidade demográfica de cada área do IBGE e depois precisou medir o tamanho das áreas das favelas." (a36, eC).

"Sim, porque o número de moradores e da Densidade Demográfica são grandes e com o resultado da prefeitura e do IBGE é meio complicado saber a numeração certa sobre esse assunto. $"(\mathrm{a} 39, \mathrm{eC})$.

“Ele tem dificuldades pois o IBGE não coleta dados só das comunidades (favelas) e sim de todo o bairro em volta. Com isso ele é obrigado a coletar todas as informações de novo. $\mathrm{E}$ lembrando que nem sempre a população quer participar." (a9, eA).

O primeiro argumento desenvolvido pelo estudante a36 conseguiu identificar na fundamentação utilizada pelo pesquisador os procedimentos metodológicos para responder ao problema dos dados diferentes entre o IBGE e a Prefeitura de São Paulo ("Ele teve que pesquisar a densidade demográfica de cada área do IBGE e depois precisou medir o tamanho das áreas das favelas"). Além disso, ele identificou a produção de dados feitas pelo pesquisador ao perceber a necessidade dele de "(...) comparar as áreas nos locais em que haviam confusões entre a prefeitura e o IBGE".

O estudante buscou no procedimento realizado pelo cientista elementos para validar a afirmação e torná-la uma sequência argumentativa mais forte. No entanto, ainda faz falta a apresentação de justificações de como a metodologia desenvolvida explica a afirmação de que existem dificuldades em medir o tamanho da população residente nas favelas de São Paulo e, ainda, a apresentação de refutação ao argumento contido no cenário sociocientífico.

O segundo texto escrito desenvolvido pelo aluno a39 se utiliza de dados como garantia para sua argumentação na sequência: "porque o número de moradores e da Densidade Demográfica são grandes" e da justificação ("o resultado da prefeitura e do IBGE é meio complicado saber a numeração certa sobre esse assunto.") para sua conclusão ("Sim").

Apesar do uso de mais de um elemento argumentativo, percebe-se no desempenho do estudante um fraco domínio conceitual sobre o dado de densidade demográfica e também o uso de dados que não possuem garantias, e que estão relacionados a uma predefinição sobre o contexto socioespacial das favelas paulistanas.

A justificação baseada em um padrão intuitivo de compreensão do problema ("Dados grandes" maior dificuldade de se chegar a uma conclusão) é também compatível com outros argumentos que receberam esta identificação Conclusão (C), Dados (D) e Justificações (J), como o que apresentamos anteriormente no gráfico 1.

O terceiro argumento escrito pelo aluno a9 foi identificado como uma sequência argumentativa C-F-J, pois os elementos argumentativos utilizados para garantir sua conclusão ("Ele tem dificuldades") foram o apoio à fundamentação do cientista, mais explicitamente, à hipótese desenvolvida pelo pesquisador ("pois o IBGE não coleta dados só das comunidades (favelas) e sim de todo o bairro em volta") e à metodologia ("Com isso ele é obrigado a coletar todas as informações de novo").

A fundamentação para o trecho sobre a metodologia demonstra também um erro de entendimento do estudante sobre os procedimentos adotados pelo pesqui- 
sador, que não envolveram a mesma metodologia do IBGE de coleta de dados e sim o uso dos dados de densidade demográfica para os setores censitários em relação ao tamanho da área das favelas não consideradas pela metodologia do IBGE.

Um outro seguimento, "E lembrando que nem sempre a população quer participar", foi identificado como uma justificação, já que o estudante busca um apoio para as dificuldades encontradas pelo pesquisador na falta de participação da população. A presença dessa asserção do estudante demonstra uma operação epistêmica presente na argumentação em que não se avaliam as dimensões das afirmações dadas, um contexto sociocultural cientificamente não previsto, calcado na aparência das coisas, portanto, sem validade cientifica. Associando este seguimento do texto escrito ao anterior que apresentava a metodologia percebe-se que o erro do estudante sobre os procedimentos adotados pelo pesquisador permanece implícito em sua compreensão sobre as soluções propostas na pesquisa.

Os seguimentos quádruplos identificados apresentaram as seguintes sequências: C-F-J-R e C-D-J-R. Uma característica inicial desta análise é a de que todos estes seguimentos apresentam a refutação como um elemento a mais que compõe a asserção. Assim, como apresentamos para as sequências anteriores seguem-se trechos escritos para a demonstração da tomada de valor quanto aos elementos da TAP.

\footnotetext{
"Porque, muitas vezes, os números da "prefeitura" não são ao certo "certos" como o do IBGE as vezes as favelas já foram "destruídas" e está no sistema ainda ou aparecem mais favelas e não é contado com as outras." (a38, eC).

"Talvez o pesquisador não tenha condições para afirmar pois o sentido de favela é muito amplo, o pesquisador pode não saber o significado de favela para a prefeitura e para o IBGE." $(\mathrm{a} 45, \mathrm{eC})$.

"Sim, pois os dados da prefeitura e os dados segundo a pesquisa realizada pelo IBGE são bem diferentes. Sabendo disso a margem de erro para a tal pesquisa é realmente muito grande. Lembrando que os dados pesquisados de ambas as partes são só estimativas, não estão ao "certo" correta." (a47, eC).
}

Uma das principais dificuldades para a identificação da sequência elaborada pelo aluno a38 são as críticas apresentadas por diferentes autores ${ }^{27}$, quanto a duplicidade das categorias na TAP, como a dificuldade em se distinguir na prática dados de justificações, ou como nos exemplos apresentado, a refutação a fundamentação da pesquisa apresentada.

Por isso, na contraposição desenvolvida pelo estudante ao cenário sociocientífico, os seguimentos foram identificados em uma dupla classificação, como no caso do seguimento da resposta: “os números da 'prefeitura' não são ao certo 'certos' como o do IBGE", em que a refutação feita atinge diretamente a hipótese do pesquisador (Fundamentação - F).

A justificação (J) adotada pelo estudante para qualificar sua refutação à hipótese do pesquisador foi identificada no seguimento ("as vezes as favelas já foram "destruídas" e está no sistema ainda ou aparecem mais favelas e não é contado com as outras.").

27 Erduran, Simon \& Osbourne, 2004; Duschl, 2007 e Jiménez-Aleixandre \& Brocos, 2015. 
Na resposta escrita pelo estudante a45 identificamos também a mesma sequência (C-F-J-R). O seguimento: "Talvez o pesquisador não tenha condições para afirmar pois o sentido de favela é muito amplo" foi identificado como uma refutação $(\mathrm{R})$ à fundamentação $(\mathrm{F})$, ao cenário sociocientífico apresentado e à justificação (J) (“o pesquisador pode não saber o significado de favela para a prefeitura e para o IBGE."). Apresenta a possibilidade de que a forma de classificar das instituições pode ser apontada como o motivo da divergência.

Como neste caso, a hipótese elaborada pelo estudante é convergente ao estudo de Torres \& Marques e Bon Junior ${ }^{28}$ que apontam para esta divergência na definição dos conceitos de setores anormais (IBGE) e de favela (Prefeitura de São Paulo). Consideramos que a contraposição apresentada demonstra uma lacuna quanto a apresentação dos conceitos no cenário sociocientífico que elaboramos para a coleta de dados.

A resposta elaborada pelo estudante a47 apresenta como garantias a conclusão ("Sim"), um seguimento de dados ("pois os dados da prefeitura e os dados segundo a pesquisa realizada pelo IBGE são bem diferentes"), um seguimento de justificação ("Sabendo disso a margem de erro para a tal pesquisa é realmente muito grande") e a refutação ("Lembrando que os dados pesquisados de ambas as partes são só estimativas, não estão ao "certo" correta.").

A análise das dimensões da qualidade dessa argumentação reflete uma condição em que são apresentadas incorreções nas relações entre a justificação e a refutação. A interpretação de que a diferença entre os dados das duas instituições se configure como margem de erro e de que um dado por ser apresentado como estimado esteja incorreto são definições sem validade cientifica, com grande possibilidade dessas expressões terem sido incorporadas na cultura do estudante através de seu uso pela imprensa em períodos eleitorais, por exemplo.

Na segunda etapa de análise buscamos organizar as informações sobre a suficiência dos dados apresentada pelos estudantes, seguimos o modelo apontado por Lima $^{29}$ de identificação dos dados a partir das informações disponibilizadas pelo cenário sociocientífico.

Essa etapa ganhou nossa atenção devido ao que já havíamos apresentado anteriormente sobre a presença de sequências argumentativas que se utilizavam de dados cientificamente não válidos. A distinção entre os dados presentes no cenário sociocientífico e os apresentados sem qualquer relação aos disponibilizados refletiram asserções como: o número de pessoas que moram em favelas cresce cada vez mais, ou ainda, que o tamanho das favelas, do espaço e a configuração do espaço por elas ocupados refletem nas dificuldades encontradas pelo pesquisador (por exemplo, "porque tem muita gente na favela e é muito fechado").

Com relação a este aspecto, os textos escritos que apresentaram dados sem relação com as informações fornecidas no cenário sociocientífico foram identificados

28 Torres \& Marques, 2002 e Bon Junior, 2005.

29 Lima, 2008. 
nesta sequência de análise como argumentos que não se utilizam de dados disponibilizados. Para um parâmetro dessa incidência nas respostas identificamos que 24 estudantes dos argumentos apresentam o elemento argumentativo "dados", mas que em 11 destes os dados traduzem-se em leituras preconcebidas pelos estudantes, sem validade científica e/ou que não se referem aos dados disponíveis. Outro ponto reflexivo para esta correlação é que mesmo para os estudantes que se utilizaram de dados fornecidos para a pesquisa, estes não exploraram suficientemente tudo o que foi disponibilizado, focando em poucos dados como garantias.

O recurso a dados como garantia para conclusões era uma relação esperada já que outros estudos já destacavam este fato, assim como, também, as dificuldades para se selecionar evidências significativas e distinguir o cotidiano da tarefa científica nas argumentações escritas por estudantes nesta faixa etária ${ }^{30}$.

A partir dessa correlação foi possível destacarmos a pouca relação entre a presença de seguimento argumentativos mais completos e apresentação da suficiência de dados disponibilizados. Este resultado é também condizente com o estudo de Sardá Jorge \& Sanmartí Puig ${ }^{31}$, mas apresenta discordância com uma tendência apontada por Lima ${ }^{32}$ da possibilidade de uma maior qualidade de dados apresentada a partir das sequências argumentativas triplas.

Nossa próxima análise buscou identificar nas sequências argumentativas mais completas que argumentos apresentavam uma relação entre os dados, a justificação para o estabelecimento de conclusões. As sequências argumentativas que correspondem a tal correlação foram: C-D-J, C-F-J, C-F-D C-F-J-R e C-D-J-R, equivalentes a 20 das respostas analisadas.

\begin{tabular}{cccc}
\hline & \multicolumn{2}{c}{ Relação entre Dados, Justificações e Conclusões n=20 } \\
$\begin{array}{c}\text { Sequências } \\
\text { Argumentativas }\end{array}$ & $\begin{array}{c}\text { Não apresenta relações ou } \\
\text { apresenta incorreções nas } \\
\text { relações que estabelece } \\
\text { entre os elementos que } \\
\text { refere }\end{array}$ & $\begin{array}{c}\text { Apresenta, com } \\
\text { correção, algumas } \\
\text { relações entre os ele- } \\
\text { mentos que refere }\end{array}$ & $\begin{array}{c}\text { Apresenta, com } \\
\text { correção, todas as } \\
\text { relaçóes entre os } \\
\text { elementos que re- } \\
\text { fere. }\end{array}$ \\
\hline C-D-J & 4 & 3 & 1 \\
C-F-J & 0 & 3 & 1 \\
C-F-D & 0 & 3 & 2 \\
C-F-J-R & 0 & 0 & 2 \\
C-D-J-R & 0 & 1 & 0 \\
\hline $\begin{array}{l}\text { Quadro 1: Relação entre Dados, justificações e Conclusões e a correlação com as sequências } \\
\text { argumentativas completas } \\
\text { Elaborado por Carli, Eden C. }\end{array}$
\end{tabular}

Dentre os resultados obtidos a partir dessa correlação verificamos que a sequência argumentativa C-D-J é a única que identificamos que apresenta incorreções ou

30 Lima, 2008; Kelly \& Takao, 2001; Sunal, Sunal \& Tirri, 2001; Erduran, Simon \& Osborne, 2004, Sardá Jorge \& SanMartí Puig, 2000.

31 Sardá Jorge \& SanMartí Puig, 2000.

32 Lima (2008) 
falta de relações entre os elementos que refere. Uma primeira explicação para o resultado pode ser o número maior de respostas que se enquadram nessa sequência argumentativa em relação as outras sequências, mas por ser um resultado diferenciado consultamos novamente as respostas que se enquadram nesta correlação para tentar distinguir os motivos relativos a esta situação. $\mathrm{O}$ argumento abaixo foi selecionado como um exemplo dos problemas relacionados a este padrão:

(Sim) "Ele tem porque, ele viveu um pouco dessas comunidades, ele teve muita dificuldade para pode chegar num resultado. O resultado dele foi a tabela, e também quanto mais tem gente vivendo numa área, maior a densidade demográfica." (a43, eC).

Conforme se apresenta no argumento desenvolvido pelo estudante a43, as garantias para apoiar a conclusão ("Sim, ele tem porque...") se utilizam de justificação ("ele viveu um pouco dessas comunidades, ele teve muita dificuldade para poder chega num resultado") e de dados ("O resultado dele foi a tabela, e também quanto mais tem gente vivendo numa área, maior a densidade demográfica") que não estabelece relações e apresenta incorreções nas relações entre os elementos que refere.

Já havíamos reportado anteriormente a apresentação de dados preconcebidos que os estudantes usaram como recurso para qualificar suas conclusões, mas a presença de justificações que também se sustentam sobre a aparência das coisas também pode ser identificada nesta sequência. No caso do estudante a43, se exemplifica a impressão de que a vivencia do pesquisador é uma garantia que apoia sua conclusão.

Retomando aos resultados do quadro 1, as relações entre os elementos argumentativos apresentam mais elementos nas sequências em que os estudantes conseguem identificar a fundamentação da pesquisa, com melhores resultados no seguimento C-F-J-R. Não foi possível diagnosticar a relação entre sequências argumentativas mais completas e um maior nível de relação entre dados, justificações e conclusões, conforme uma das conclusões apresentas por Lima ${ }^{33}$. Mas, ressaltamos que para os dois diagnósticos apresentados há uma baixa incidência de amostras que dificulta a generalização desses diagnósticos.

A identificação de limitações do estudo (refutação) demonstrou o pouco uso desse elemento por parte dos estudantes ( 3 em números absolutos). De certo modo o pouco uso da refutação na constituição de argumentos foi observado por Erduran, Simon \& Osbourne ${ }^{34}$ e também foi um dos problemas encontrados por Lima ${ }^{35} \mathrm{em}$ suas pesquisas com estudantes.

O reconhecimento de dificuldades no desenvolvimento da refutação, trazidas nessas diferentes pesquisas, colocam-nos em posição de examinarmos essa categoria e a importância dessa atribuída pelos diferentes pesquisadores que buscaram entender tal processo na argumentação de estudantes. Nossos resultados confirmam

33 Lima (2008).

34 Erduran, Simon \& Osbourne (2004).

35 Lima (2008). 
as dificuldades dos estudantes em elaborar a refutação de dados, justificação e/ou da fundamentação e já induzem possíveis necessidades metodológicas em sala de aula.

A refutação tem um papel central para a proposta de Alfabetização Cientifica, para compreendermos a qualidade da argumentação cientifica, segundo a TAP e também para entendermos as relações entre as mudanças paradigmáticas do conhecimento cotidiano e do conhecimento científico, dentre outras coisas:

- Por demonstrar a forma com que os estudantes compreendem a linguagem científica (a validade das evidências e a justificação oferecida);

- Por proporcionar a discussão sobre a construção de "verdades" cientificas e a reinvindicações de mudanças epistemológicas;

- Ao mesmo tempo, por demonstrar que argumentos sem refutação mantém as afirmações num contexto eterno, sem mudanças na mentalidade e na evolução da qualidade dos argumentos.

Os argumentos que contém o elemento refutação já foram anteriormente apresentados e neste incorremos o destaque a contraposição em relação às limitações das fontes de informação ou da suficiência do estudo realizado pelo cientista. Mas, também, demos destaque a refutação produzida pelo estudante a47 que fez uso de informações sem validade científica. Este exemplo serve também de alerta da necessidade de não esquecermos de que a refutação é importante para um pensamento crítico, mas para que incorra em um processo de Alfabetização Científica é importante para o estudante selecionar evidências significativas.

O enunciado da questão 2 e 3 tinha como objetivo avaliar a capacidade de identificação de evidências empíricas e de explicações causais. A perspectiva que adotamos nesta etapa envolve uma importante habilidade no aprendizado que é a de usar, acessar, e criticar evidências, habilidade esta que inclui o entendimento sobre as relações entre os dados, as justificações e as conclusões e de Alfabetização Cartográfica em que se tem como expectativas que os estudantes saibam analisar uma carta temática extraindo elementos fundamentais.

Referentes a suficiência dos dados apresentados na questão 2 verificou-se que a maioria dos estudantes conseguiu extrair dados contidos no material cartográfico (28 estudantes). Mas, um número expressivo ainda demonstrou dificuldades na apresentação de dados ( 19 estudantes).

A análise mais aprofundada sobre as respostas que não se referiram a dados fornecidos pelo mapa identificou que os estudantes que não fizeram referências a dados em geral apresentaram outros elementos do mapa (como a fonte dos dados), partes do texto que apresentam informações não significativas para a resposta (como a definição de densidade demográfica, dados da tabela, a questão problema 
do estudo, etc.) e a referência a localização do exemplo dado como o meio que ajudou o pesquisador a organizar a pesquisa ${ }^{36}$.

Já a análise da questão 3, que pedia para os estudantes identificarem um resultado empírico obtido pelo pesquisador demonstra resultados muito divergentes a amostra apresentada para a questão 2, com 32 dos estudantes não identificando os resultados e apenas 15 identificando.

Este resultado é compatível com vários estudos ${ }^{37}$ que apontaram para uma maior dificuldade dos estudantes identificarem os resultados de estudos empíricos e uma maior facilidade dos estudantes em encontrar justificações nas pesquisas científicas.

A explicação dada por Glassner et al. ${ }^{38}$ se refere a uma maior dificuldade da identificação de resultados por parte dos estudantes devido ao recurso cognitivo que os dados implicitamente trazem de memorização, comparativamente a uma explicação de recursos cognitivos lógicos causais, apesar de Lima ${ }^{39}$ ponderar a generalização desta tese.

Como discussão sobre os resultados diferentes nestas questões, apontamos que o grau de exigência entre as duas questões não foi suficientemente ponderado, já que ao apresentarmos o mapa, em um quadro ao lado, apresentamos a explicação do cientista quando aos elementos do mapa apresentado, isso resultou em um dado que constrange uma comparação entre as questões já que uma destas apresentava recursos a mais do que outra.

A questão 2 representou também um problema de comparação com os dados de Lima ${ }^{49}$ quanto a apresentação de explicação do cientista já que o enunciado não deixou implícito a informação esperada para análise. O que fez com que os alunos se referissem a dados e explicações nos mesmos argumentos, o que dificultou um padrão comparativo.

\section{A análise da tomada de decisão dos estudantes frente à diálogos de questões sociocientíficas.}

Entender como o estudante integra o conhecimento científico ao processo de tomada de decisões sobre a prática científica foi nosso objetivo na questão 4 e tem como característica relacionar o grau de importância dado pelos estudantes e sua justificação ao mérito e a capacidade de persuasão dos dados e explicações apresentadas.

Na primeira parte dessa questão, pedimos que estes julgassem o mérito da pesquisa, das 47 respostas escritas 2 foram descartadas devido a não apresentarem jus-

\footnotetext{
36 Apesar de não ter sido nosso objetivo analisar os processos de alfabetização cartográfica desses estudantes, os dados coletados por essa questão acabaram por corroborar as análises de Simielli (2005) que já apresentava como problema a ser resolvido pela área a necessidade de mudanças de didáticas que formam estudantes copistas em didáticas que formem estudantes leitores críticos de mapas.

37 Lima, 2008; Glassner et. al., 2005; Chinn e Brewer, 1993; Sadler et al., 2002.

38 Glassner et. al., 2005.

39 Lima, 2008.
} 
tificações e 1 estudante não respondeu à questão, o que nos disponibilizou 44 respostas válidas.

Para entendermos como os estudantes julgaram o mérito da pesquisa científica apresentada, elaboramos três dimensões de análise.

A primeira dimensão apresenta os contextos que foram utilizados para justificar a importância da pesquisa, com esta dimensão de análise buscamos evidenciar os tipos de fundamentos que os estudantes utilizaram para o julgamento do mérito da pesquisa ${ }^{40}$.

A segunda dimensão expõe a análise sobre a importância dos resultados da pesquisa apresentada pelos estudantes, justificamos a inserção dessa dimensão devido aos resultados colhidos anteriormente sobre a qualidade dos argumentos dos estudantes, principalmente com relação aos dados por eles utilizados em seus argumentos.

A terceira análise buscou categorizar as justificações de acordo como o padrão observado por Sadler \& Zeidler ${ }^{41}$ de razão informal em contextos sociocientíficos na tomada de decisão, que distingue nas respostas de estudantes, expertises e leigos padrões de evidências de lógicas informais, classificados pelos autores em lógica racionalista, lógica emotiva e lógica intuitiva.

Sobre a primeira dimensão de análise, o diagnóstico das respostas escritas apontou que os estudantes fazem uso dos seguintes contextos em sua tomada de decisão:

a) Informações sobre o território: Quando o texto escrito colocou como central a defesa ou não da necessidade de dados sobre o território em contextos socioespaciais e socioeconômicas. Este agrupamento temático esteve presente em 13 das respostas válidas, com todos os alunos concordando que a pesquisa apresentada é importante. Os exemplos de respostas a seguir têm como objetivo ajudar a entender a maneira em que foi realizada sua identificação:

Exemplos:

(A pesquisa feita é importante). "Na minha opinião é importante porque os munícipes precisam ficar cientes dos dados do seu bairro, Estado e até mesmo país e os estudos científicos feito por eles podem ajudar com essas informações." (a9, eA).

(A pesquisa feita é importante). “Porque fala do tamanho da população em áreas que no futuro pode ajudar a ter uma ideia de contas pessoas tem em uma só área e a porcentagem do local e da área escolhida." (a42, eC).

40 Conforme metodologia proposta em Sadler et al., 2002.

41 O padrão racional de tomada de decisão organizado por Sadler \& Zeidler (2004) e Zeidler \& Sadler (2007) busca caracterizar as afirmações em que se percebem o uso da lógica e do conhecimento, não necessariamente afirmações que apresentem conceitos científicos, evidências empíricas, etc., mas também afirmações que demonstrem expressões racionais da moralidade. Já o padrão de razão informal de lógica intuitiva apresenta-se na forma de um argumento que o estudante escolhe não racionalizar suas afirmações, trata-se de uma reação imediata a necessidade de atender ao julgamento do mérito. O padrão de razão informal de lógica emotiva considera a apresentação da antipatia, experiências vividas e o interesse pessoal como uma forma de justificação da tomada de decisão feita pela estudante. 
Os textos escritos apresentam características quanto ao mérito apresentado pelos estudantes a pesquisa, sendo que em um dos exemplos trazidos o estudante A9 nota-se que o estudante apresenta uma importância social dos resultados, apresenta também padrões racionais de tomada de decisão quando traz como referência a necessidade dos munícipes terem informações sobre o território.

Este padrão foi considerado como próximo a afirmação do estudante A9 e do A42 que qualifica a pesquisa apresentando padrões racionais da eficiência científica dos resultados em produzir dados mais qualificadas.

b) Contexto de Pesquisa: quando se repercutiu nos textos escritos uma visão geral sobre a objetividade científica (motivos, intenções, objetivos da pesquisa), propostas de novas pesquisas, valorização da autoridade ou o questionamento da autoridade do pesquisador, a eficiência da pesquisa científica, as dificuldades cotidianas de realização da pesquisa, o contexto do trabalho do pesquisador.

Exemplos:

(A pesquisa feita não é importante) “Na minha visão o estudo só ajudaria a ver o número dos habitantes, mas não mudaria a vida de ninguém." (a25, eC).

(A pesquisa feita é importante) “É importante porque assim podemos saber qual é a quantidade de população da favela e além disso é um dado muito importante, e que pode possibilitar e abrir a porta para outras pesquisas. E também conhecimento nunca é demais." (a17, eB).

(Tenho dúvidas sobre sua importância) "Eu não entendi muito bem a importância dessa pesquisa e para o que ela serviria acredito que seja mas por curiosidade em saber o tamanho da população favelada." (a18, eB).

Neste contexto contemplam as afirmações que mais apresentaram dúvidas sobre a pesquisa ( 4 das respostas) ou de estudantes que não achavam importante a pesquisa realizada ( 2 das respostas). Neste destacamos as respostas dos estudantes que apresentaram como importância dos resultados a eficiência da pesquisa (a25 e al7) e a curiosidade (al8).

O texto escrito pelo estudante a25 apresenta um padrão que busca, em uma lógica utilitarista da ciência, o questionamento sobre a relevância da pesquisa realizada. Esta caracterização é importante pois define boa parte das afirmações que não acharam relevante o estudo apresentado.

Uma leitura contraditora sobre a eficiência da pesquisa foi a resposta dada pelo estudante al7 que relacionou aos dados a possibilidade de a informação produzir novos estudos científicos, um padrão racional de programas de pesquisa científica comumente identificado com os afazeres de pesquisadores, mas com um trecho final ("E também conhecimento nunca é demais") que não avalia a função social da produção científica.

Um outro exemplo que citamos neste contexto apresenta um padrão intuitivo de razão informal em que a curiosidade cientifica é apresentada como justificação para a afirmação sobre as dúvidas do estudante. Tanto a afirmação do estudante al 8 
quanto a do a25 apresentam razões sobre a relevância de estudos que apontam para uma leitura de distanciamento entre pesquisa cientifica e sociedade.

Este distanciamento encontrado pelos estudantes é um elemento que justifica as pesquisas sobre as discussões sociocientíficas em sala de aula como uma forma de desenvolver estratégias pedagógicas para engajar o estudante e promover uma reflexão crítica, principalmente quando se relaciona a importância da construção de conteúdos e evidências e as implicações do conhecimento científico.

Relevância pessoal: quando o texto escrito apresentou a própria experiência ou de terceiros em exemplos de caso ou, ainda, quando o argumento apresenta ilustrações sobre o próprio aprendizado como forma de valorizar a afirmação. A relevância pessoal foi apresentada em 10 das respostas válidas, com 9 dos alunos concordando que a pesquisa apresentada é importante e 1 apontando que tem dúvidas sobre sua importância.

Exemplos:

(A pesquisa feita é importante). “É importante porque traz conhecimento não só para nós, mas sim para todos e principalmente para os moradores de comunidades. Gostei muito dessa pesquisa e espero que seja feita novamente, mas com outro assunto" (all, eA).

(Tenho dúvidas sobre sua importância) “Porque tipo para algumas pessoas é importante agora para as outras não é." (a23, eB).

Neste contexto aparecem padrões emotivos (a1l) e intuitivos (a23) de razão informal. A importância dos resultados da pesquisa apresenta uma relação pessoal e comunitária para o estudante al1. Na afirmação do estudante a23 a importância da pesquisa é relativizada de acordo com o grupo de pessoas que tem acesso a esta, como a poucas informações sobre qual a relevância para cada grupo de pessoas que o estudante apresenta categorizamos esta afirmação como uma afirmação que não qualifica a importância dos dados.

O fato dos estudantes se utilizarem de crenças pessoais para julgar o mérito da pesquisa constitui-se como um elemento observado por Sadler \& Zeidler ${ }^{42}$, e que sugerem que os muitos exemplos desse tipo de atitude frente a cenários sociocientíficos demonstram a compartimentação que os estudantes realizam entre o mérito e o conhecimento científico (a cultura científica, as evidências, a fundamentação, etc) e a opinião pessoal.

Como implicação pedagógica para este tipo de ação, os autores sugerem uma importante intervenção dos professores, não para mudar o ponto de vista dos estudantes, mas, principalmente, na promoção de uma integração da cultura científica (o uso de evidências, fundamentação, conhecimento científico, etc) para um processo de Alfabetização Científica mais profundo.

42 Sadler \& Zeidler, 2004 e Zeidler \& Sadler, 2007. 
Direitos: Quando o texto escrito coloca como central a defesa de direitos (a acesso a bens e informações e a não distinção) para uma melhor justiça social, ou ainda, quando o argumento tem como central a apresentação de regras e princípios gerais morais sem a necessidade de uma fundamentação científica ou jurídica. Neste contexto se identificaram 4 dos argumentos válidos que julgaram a pesquisa importante.

\section{Exemplo:}

(A pesquisa feita é importante) "É uma pesquisa que pode ajudar a parte do governo, ajuda a diminuir o número de favelas "comunidades» em São Paulo e melhorar a condição de vida das pessoas que moram nessas comunidades. Portanto na minha opinião é que é importante a pesquisa sim." (a38, eC).

A resposta do estudante a38 demonstra características desse contexto em que todos os outros estudantes apresentaram um padrão de razão informal racional. Neste contexto os resultados da pesquisa foram sempre apresentados como relevantes socialmente para a garantia do direito à moradia e do bem-estar da população que reside em favelas.

Segurança: Quando o texto escrito coloca como central o tema da segurança ou da insegurança (violência).

Exemplo:

(Tenho dúvidas sobre sua importância). “Tenho dúvidas tipo para que isso vai servir, vai servir para determinar os locais de São Paulo um pouco perigoso? Se for para isso seria muito importante os resultados e importante que a população saiba disso, porque muita gente não sabe onde está andando e pode correr risco." (a4l, eC).

A resposta a4l constitui-se como o único texto escrito neste contexto para a questão 4, para categorização do padrão de razão informal, classificamos este argumento como racional e para categorização da importância dos resultados da pesquisa utilizamos, também, a categoria "segurança".

Esta resposta aponta, assim como a pesquisa de Sadler et al..$^{43}$ antecipava, para constatações sobre a influência dos riscos, consequências e preocupações sobre os resultados apresentados por pesquisas científicas, neste contexto se percebe, também, uma leitura utilitarista da ciência como um sinal de alerta para possíveis consequências ou danos pessoais e sociais.

Retomando os objetivos dessas análises, entendemos que o processo de decisão dos estudantes na construção da argumentação cientifica constitui-se como um elemento importante para que os professores reflitam sobre a necessidade dos estudantes envolverem-se em reflexões críticas a partir de suas próprias posições e de seus pares.

43 Sadler et al., 2002. 
Sensação e Manifestação: Quando o argumento tem como central um padrão emotivo e transmissão de sensações quanto ao cenário sociocientífico. Neste contexto muitos argumentos apresentaram como central a manifestação de simpatia ou antipatia com a pesquisa, o pesquisador e/ou a fundamentação e, também, a indignação e a contestação a sociedade, a governos, a imprensa, etc.

\section{Exemplos:}

(A pesquisa feita é importante). “Na minha opinião é muito importante porque comprovou que eles dão um pouco de importância para as favelas não a importância que devia dar, mas... "( $\mathrm{a} 10, \mathrm{eA})$.

(A pesquisa feita é importante). “É importante saber o nível de pobreza real do nosso próprio ambiente não se pode + acreditar cegamente no que é visto sair da boca da imprensa. E é dever da população se interessar nesses aspectos e querer saber com intuito de ajudar o que é omitido para população. Então sim é muito importante." (a33, eC).

Todos os textos escritos neste contexto foram categorizados como argumentos que se utilizam de um padrão de razão emotivo como forma de apoio para suas afirmações. Os padrões emotivos são considerados por Sadler \& Zeidler ${ }^{44}$ como elementos fundamentais para entender o valor dos contextos sociocientíficos para a Alfabetização Científica, para os autores a presença desse tipo de atitude frente a tomada de decisões sobre o conhecimento científico é significativa da necessidade de se refletir sobre as emoções nas salas de aula, que quando negligenciadas inibem o desenvolvimento pessoal dos estudantes.

Em vista do cenário sociocientífico, uma outra análise realizada submeteu os argumentos feitos a questão 4 a uma classificação sobre qual foi a importância dos dados da pesquisa apresentados pelos estudantes. O quadro 2 indica a distribuição das categorias que organizamos para esta dimensão de análise.

\begin{tabular}{lc}
\hline Importância dos resultados da pesquisa apresentados pelos estudantes. \\
\hline Importância Científica & 8 \\
Importância Pessoal & 7 \\
Importância Social & 14 \\
Fornece informações para Segurança das pessoas & 1 \\
Curiosidade & 2 \\
Não qualifica a importância dos resultados & 8 \\
Importante apenas para o pesquisador & 1 \\
Refuta a importância dos resultados & 1 \\
Causou Indignação & 2 \\
Amostras descartadas & 3 \\
\hline Quadro 2: Importância dos resultados da pesquisa apresentados pelos es- \\
tudantes
\end{tabular}

44 Sadler \& Zeidler, 2004 e Zeidler \& Sadler, 2007. 
Conforme o apresentado alguns estudantes não qualificaram a importância dos resultados da pesquisa ( 8 estudantes) ou ainda, refutaram a importância dos resultados ( 2 estudantes), mas a maior parte dos estudantes ( 34 estudantes) buscou relacionar diferentes possibilidades de se interpretar a importância dos resultados da pesquisa.

Uma última análise, aos argumentos dos estudantes para a questão 4, foi feita a partir do modelo de classificação da tomada de decisões proposto por Sadler \& Zeidler, que propôs classificar os padrões de razão informal em três tipos: Racional, Intuitiva e Emotiva. Os resultados dessa classificação se apresentam no quadro 3.

\begin{tabular}{lr}
\hline Padrões de razão informal & \\
\hline Racional & 25 \\
Intuitiva & $\mathbf{1 4}$ \\
Emotiva & $\mathbf{5}$ \\
\hline
\end{tabular}

Quadro 4: Padrão de Razão Informacional dos argumentos (amostras válidas analisadas $=44$ ) Elaborado por Carli, Eden C..

Em seus estudos Toulmin ${ }^{45}$ já admitia esse tipo de debate em que os argumentos estão sujeitos a outras racionalidades, mas não a outras lógicas racionais, o que fez com que mantivesse a importância de seu layout. Por trás de tal afirmação está a leitura de Toulmin de que mesmo nas chamadas "Hard Science" as concepções de argumentos também moldam e são moldadas por questões morais, sensatez, insensatez e solecismos.

A presença desse debate no campo de análise dos argumentos científicos se relaciona principalmente ao conceito de cidadania e a afirmação inicialmente já apresentada por Erduran \& Jiménez-Alexandre ${ }^{46}$ de ciência para todos. Admite-se, assim, que para a conformação da análise dos argumentos em sala de aula as dimensões sociais dos argumentos dos estudantes não é só um dado presente, mas algo que se desenvolve de forma legitima e desejável na formação dos estudantes em ciências ${ }^{47}$.

Considerando tais lógicas utilizados na análise dos padrões de razão informal consideramos importante destacar a afirmação de Sadler \& Zeidler de que: separar a aprendizagem de conteúdo, da aplicação e de suas implicações é um divórcio tão artificial que não consegue nem dar conta de explicar a produção do conhecimento científico nem a aprendizagem deste na sala de aula ${ }^{48}$.

\section{Considerações Finais}

O objetivo dessa investigação foi o de analisar quais são e como são desenvolvidos os argumentos científicos construídos pelos alunos dos anos finais do ensino funda-

45 Toulmin, 2001

46 Erduran \& Jiménez-Alexandre, 2007.

47 Kolstø \& Ratcliffe, 2007.

48 Zeidler \& Sadler, 2007, p. 210. 
mental, em meio a situação de aprendizagem a partir do conceito de território. Para atingir tais objetivos foram relacionados como indicadores para pesquisa a análise dos aspectos relativos a qualidade do argumento desenvolvido pelos alunos e os fundamentos utilizados pelos estudantes sobre dilemas sociocientífico.

\section{$\left.1^{\circ}\right)$ Conclusões a respeito do indicador que buscava fornecer subsídios para a compreensão da aquisição do discurso científica pelos alunos:}

O enunciado da questão 1 teve como objetivo a avaliação da qualidade da argumentação dos estudantes que participaram da pesquisa na discussão do cenário sociocientífico apresentado. Foram utilizados como procedimentos de análise:

o diagnóstico das sequências argumentativas, caracterizando os argumentos por maior complexidade a partir da presença de mais elementos previstos em um argumento científico, segundo a TAP.

o diagnóstico sobre a suficiência dos dados; sobre a relação entre dados, justificações e conclusões, sobre as limitações do estudo (refutação) e sobre a validade científica das informações não fornecidas.

Sobre os procedimentos adotados, encontramos como resultados:

A maior parte dos estudantes não fizeram uso de sequências argumentativas mais completas (com três ou mais elementos argumentativos). Essa falta de desenvolvimento de mais garantias é um elemento importante para compreendermos a necessidade de também se ensinar a argumentar, afim de produzir asserções que corroboram a tese de que o uso de mais elementos argumentativos aumenta a força de persuasão das conclusões tomadas ${ }^{49}$.

A maior parte dos estudantes não avaliou corretamente o estudo do cientista. Nesse aspecto, percebe-se que muitos estudantes fizeram uso de contextos socioespaciais cientificamente não previstos, calcados na aparência das coisas e relacionados a uma predefinição sobre a realidade das favelas paulistanas. Alguns outros erros apresentados ocorreram na apresentação de outros procedimentos que não os adotados pelo pesquisador e no fraco domínio sobre o conceito de densidade demográfica.

A análise sobre a suficiência de dados confirma que o recurso a dados como garantia para conclusões é bastante acionado pelos estudantes. No entanto, os argumentos analisados indicam as dificuldades para se selecionar evidências significativas e distinguir o cotidiano da tarefa científica. Corroborando com as preocupações no ensino de ciências de que para a transformação de informação em conhecimento é preciso compreender a presença da alternativa plausível, o problema apresentado e a justificativa das conclusões como uma forma de possibilitar um raciocinio profundo.

A categorização dos contextos dos argumentos em relação a identificação da validade científica das informações não fornecidas, demonstrou que os estudantes apresentaram como justificações o recurso a autoridade do pesquisador, o uso de

49 Erduran, Simon \& Osbourne, 2004. 
manifestações intuitivas, contextos socioespaciais e contextos sociocientíficos novos em relação ao apresentado pela pesquisa

Mesmo nos estudantes que se utilizaram de dados fornecidos pela pesquisa foi detectado que a maioria não explorou suficientemente todos os dados disponíveis focando em poucos como garantias.

A maior apresentação de elementos argumentativos não indicou a melhor qualidade dos dados apresentados pelos estudantes, conforme a tendência apontada pelo estudo de Lima ${ }^{50}$. Este resultado implica na necessidade de um aprofundamento das discussões sobre o uso de dados para sustentar as conclusões com os estudantes.

Nossos resultados confirmam as dificuldades dos estudantes em elaborar a refutação a dados e/ou da fundamentação e já induzem possíveis necessidades metodológicas em sala de aula e de pesquisas em educação. Já a apresentação das refutações desenvolvidas indicou a crítica a hipótese, fundamentação e dados da pesquisa apresentada e demonstram as possibilidades de formação de um pensamento crítico por proporcionar a discussão sobre a construção de "verdades" científicas e a evolução da qualidade dos argumentos em estudantes.

O enunciado da questão 2 e 3 tiveram como objetivo averiguar se os alunos conseguiam identificar Dados e Justificações num conjunto de informações facultadas apresentadas em linguagem cartográfica e em uma tabela. Sobre os argumentos apresentados pelos estudantes encontramos como resultados:

A maioria dos estudantes conseguiu extrair dados utilizados pelo pesquisador no mapa (28 estudantes), mas um número expressivo ainda demonstrou dificuldades de interpretação dos dados no mapa (19 estudantes). A análise das respostas que não se referiram a dados identificou que os estudantes em geral apresentaram outros elementos do mapa (como a fonte dos dados), partes do texto que apresentam informações não significativas para a resposta e a referência a localização do exemplo dado como o meio que ajudou o pesquisador a organizar a pesquisa.

A análise da questão 3 aponta para uma maior dificuldade de os estudantes identificarem os resultados de estudos empíricos e uma maior facilidade dos estudantes em encontrar justificações nas pesquisas científicas.

Ajuizamos a respeito dos resultados apresentados nesta etapa para a reflexão de outras possibilidades de investigá-los já que consideramos que o grau de exigência entre as duas questões não foi suficientemente ponderado.

A variedade de análises propostas demonstra uma série de obstáculos a aprendizagem dos estudantes em contato com o discurso científico oferecido pela atividade. Dentre elas ressaltamos as dificuldades de se trabalhar com evidências científicas, como a identificação de resultados e dados em diferentes linguagens (mapas e tabelas), o uso de dados com garantias científicas como uma forma de apoio as conclusões e a refutação as evidências apresentadas.

50 Lima, 2008. 
Outro elemento que pode ser caracterizado como obstáculo a aprendizagem diz respeito a forma de comunicar as conclusões feitas pelos estudantes com sequências argumentativas menos completas, o que evidencia a baixa capacidade de persuasão dos argumentos que muitos estudantes elaboraram, isto está relacionado diretamente com a capacidade e a força dos argumentos produzidos.

Esses resultados indicam que a dimensão de análise sobre a qualidade da argumentação cientifica é uma significativa ferramenta para a identificação de obstáculos a aprendizagem de estudantes em Geografia por avaliar a capacidade dos estudantes a aderirem a novas evidências. Os resultados nesta pesquisa não indicam condições para a apreendermos em processos formativos, por se reportarem a avaliação de um produto, mas nos ajudam a reconhecer como importante implicação para a sala de aula, como:

O desenvolvimento de sequências didáticas e situações problemas que incentivem os estudantes a checar suas evidências (dados e justificativas). A importância do desenvolvimento de sequências didática é propícia para que o avanço das mudanças teóricas dos estudantes não signifique a produção de uma verdade temporariamente implícita para agradar a autoridade do professor, mas como um caminho que possa promover mudanças teóricas racionais e reflexivas nos alunos. Há importantes estudos sobre a argumentação ${ }^{51}$ e sobre a importância dos dados para a mudança teórica ${ }^{52}$ que reforçam essa necessidade.

O desenvolvimento de enunciados capazes de fomentar a produção de refutação pelos estudantes é uma implicação que envolve tanto o trabalho do professor, como a produção de materiais e livros didáticos. Estes resultados demonstram a pouca presença desse elemento nos argumentos dos alunos, mas também por apresentarem a demonstração de possibilidades de desenvolvimento do raciocínio crítico a partir dos poucos argumentos que apresentaram as limitações no estudo do cientista. Há importantes estudos sobre a argumentação ${ }^{53}$ que reforçam essa necessidade. Ressalta-se a oportunidade de desenvolvimento desse elemento também na contraposição a evidências e justificações em argumentos falados em dinâmica da sala de aula ${ }^{54}$.

Os resultados indicaram que a maior parte dos estudantes não fizeram uso de sequências argumentativas mais completas. Isso implica na necessidade de ensinar a argumentar e os componentes argumentativos para que os alunos produzam argumentos mais persuasivos. Essa proposta é apoiada por Erduran, Simon \& Osborne ${ }^{55}$ que indicam como um próximo passo a evolução e melhora dos argumentos a capacidade das evidências e fundamentações em justificar as conclusões chegadas. Em Jiménez-Aleixandre se aponta que ensinar a argumentar também é propiciar

51 Sunal, Sunal \& Tirri, 2001; Erduran, Simon \& Osborne, 2004

52 Chinn \& Brewer, 1993

53 Jiménez Aleixandre, 2010; Erduran, Simon \& Osborne, 2004.

54 Conforme Erduran, Simon \& Osborne, 2004; Pontecorvo \& Girardet, 1993; Jiménez Aleixandre \& Brocos, 2015.

55 Erduran, Simon \& Osborne, 2004 
experiências que possibilitem ao aluno argumentar, sendo que isso "ocurre si el diseño de tareas y del ambiente, clima a cultura del aula, favorece sus experiencias con la argumentación".

\section{$2^{\circ}$ ) Conclusões a respeito do indicador que buscava fornecer subsídios para com- preender a aproximação da argumentação científica, produzida pelos estudan- tes, da prática cidadã:}

O enunciado da questão 4 teve como objetivo analisar se os estudantes consideram normas de diferentes valores: o uso de princípios morais como garantia, (e/ou) o emprego de experiências vividas e/ou considerações sobre direitos nas justificações e caracterizar os tipos de fundamentos que foram utilizados pelos alunos na defesa de sua justificação.

Sobre os procedimentos adotados, obtivemos como resultados uma variedade de fundamentos aos quais os estudantes fizeram uso para justificar suas conclusões quanto ao mérito da pesquisa ou ao dilema sociocientífico apresentado. A análise destes contextos antecipa possíveis problemas e implicações para a pratica pedagógica e possíveis pesquisas a serem realizadas que busquem discutir o mérito e a tomada de decisão dos estudantes, como:

Alguns estudantes não qualificaram a importância dos resultados da pesquisa (em 8 argumentos) ou ainda, refutaram os resultados (em 2 argumentos), mas a maior parte dos estudantes (em 34 argumentos) buscou relacionar diferentes possibilidades de se interpretar os resultados da pesquisa. Esse diagnóstico sugere um exame sobre as positividades do cenário sociocientífico apresentado, por estimular o conhecimento científico e as formas científicas de pensar para fins individuais e sociais, inclusive por estimular os estudantes a discutir a produção de dados para a interpretação de dinâmicas territoriais, sejam sobre as possibilidades de pesquisa, seja sobre a importância social e pessoal, ou a refutação dos resultados.

Alguns estudantes se utilizarem de crenças pessoais para julgar o mérito da pesquisa sugerindo que os muitos exemplos desse tipo de atitude, frente ao cenário sociocientífico, demonstram a compartimentação que os estudantes realizam entre o mérito e o conhecimento científico (a cultura científica, as evidências, a fundamentação, etc.) e a opinião pessoal.

Alguns estudantes apresentaram fundamentos sobre a relevância de estudos que apontam para uma leitura de distanciamento entre pesquisa cientifica e sociedade.

A análise do padrão de razão informal detectou a presença de padrões racionais, intuitivos e emotivos na tomada de decisão dos estudantes. Esta ferramenta se mostrou importante para detectarmos que

Os padrões racionais, em que se percebem o uso da lógica e do conhecimento, nem sempre são sustentados por evidências e fundamentação cientificamente validas, ou com a apresentação de programa de pesquisa científica comumente identificado com os afazeres de pesquisadores. Destacam-se nesse padrão outros fun- 
damentos como uma lógica utilitária do conhecimento científico e a influência dos riscos, consequências e preocupações sobre os resultados apresentados pelas pesquisas científicas na tomada das decisões dos estudantes.

A presença de padrões emotivos nos fundamentos desenvolvidos demonstrou que a pesquisa apresentada foi relevante para a vida dos estudantes que manifestaram suas emoções.

O fato desse fator ser negligenciado muitas vezes nas salas de aula reforça a importância dos resultados e a valorização dos contextos sociocientíficos para a Alfabetização Científica.

Os padrões intuitivos revelaram outra possibilidade para entendermos as razões informais de tomada de decisão dos estudantes normalmente tem como característica argumentos que parecem bastante limitados, mas com esta categorização das informações apresentadas pelos estudantes foi possível percebermos que contextos foram utilizados e repercuti-los em implicações educativas, como: a necessidade de incentivar os estudantes a checar suas evidências (dados e justificações), de se discutir o papel social das ciências e as limitações da ciência, também nos debates da Geografia.

O estudo sobre as fundamentações que foram utilizados pelos alunos na defesa de suas justificações revelaram a importância das pesquisas e práticas em sala de aula das discussões sociocientíficas como um meio de engajar o estudante e promover uma reflexão crítica relacionada a construção de conteúdos, evidências, implicações e consequências do conhecimento científico. Ajudaram-nos também a reconhecer como importante implicação para a sala de aula nos itens que seguem:

Na importância da intervenção dos professores, não para mudar o ponto de vista dos estudantes, mas, principalmente, na promoção de uma integração da cultura científica (o uso de evidências, fundamentação, conhecimento científico, etc.), na necessidade deles se envolverem em reflexões críticas de suas próprias posições e padrões de argumento, bem como, os de seus pares para um processo de Alfabetização Científica mais profundo.

A presença de padrões racionais são apenas a expressão de um tipo de habilidade para a tomada de decisões. Por outro lado, padrões emotivos e intuitivos são tipicamente presentes em questões sociocientíficas, o que sugere a necessidade de oportunizar a expressão de ideias pessoais sobre os problemas em um ambiente em que seus pensamentos sejam valorizados.

Para combatermos uma possível análise com status de neutralidade da fundamentação dos estudantes entendemos como implicações pedagógicas a necessidade da promoção da confrontação dos argumentos, com a participação do discurso do outro $^{56}$ de outras reflexões que busquem articular a aprendizagem em Geografia e as concepções democrática, visando uma formação cidadã.

Este estudo revela a variedade de pontos de vista e ferramentas para o incremento do conhecimento científico dos estudantes. Em nossa pesquisa o conceito de

56 Arendt, 2000 e 2015. 
território esteve implicitamente relacionado a proposta de Haesbaert de uma abordagem relacional, que buscou apresentar as múltiplas relações sociais e culturais, inclusive a necessidade de entender a vivência das pessoas nestes territórios, suas subjetividades e suas territorialidades ${ }^{57}$.

Partindo da hipótese sobre o uso da argumentação científica para a aprendizagem em Geografia buscamos elencar as potencialidade e obstáculos à aprendizagem sobre o conceito de território que os professores podem trabalhar em sala de aula, pois encaramos que, em nossos resultados disponibilizamos aos educadores possibilidades de se refletir sobre suas práticas e garantir os objetivos de uma alfabetização científica em fortalecer a cidadania dos estudantes.

Reconhecemos as limitações dos resultados alcançados, tal como foi abordado ao longo dessa apresentação, porém, ressaltamos as potencialidades do estudo no campo da argumentação que evidenciam novos passos para as pesquisas e prática em sala de aula na disciplina de Geografia.

Para todos que ajudaram nessa investigação e a todos que buscam uma educação de melhor qualidade ressalvamos nosso compromisso de desenvolvimento de debates educacionais que tenham a capacidade de fornecer conhecimentos poderosos que possibilitem a nova geração participar dos debates da ciência geográfica e das interações entre ciência, tecnologia, sociedade e meio ambiente.

\section{Bibliografía}

ARENDT, Hannah. A vida do espírito (vol.l - o Pensar). Rio de Janeiro: Relume Dumará, 2000.

ARENDT, Hannah. Eichmann em Jerusalém - Um relato sobre a banalidade do mal. São Paulo: Companhia das Letras, 2015.

BACHELARD, Gaston. A formação do espirito científico: contribuição para uma psicanálise do conhecimento. Rio de Janeiro: Contraponto, 1996.

BON JUNIOR, Waldemar. Planejamento e urbanização de favelas: caracterização sócioeconômica-ambiental de favelas a partir de dados censitários do IBGE. Dissertação de Mestrado apresentada à escola politécnica da Universidade de São Paulo. São Paulo, 2005.

BUDKE, Alexandra; SCHIEFELE, Ulrich; UHLENWINKEL, Anke. I think it's stupid' is no argument: investigating how argue in writing, Teaching Geography, v. 35, n.2, summer, 2010.

CHINN, Clark A.; BREWER, William F. The role of anomalous data in knowledge acquisition: a theoretical framework and implications for science instruction, Review of Education Research. v.63, n.1, 1993.

DUSCHL, Richard A.Quality argumentation and epistemic criteria.IN:Argumentation, Science Education: perspectives from classroom-based research / organizado por: Jiménez-Alexandre; Erduran, Sibel. Alemanha: Springer, 2007.

57 Haesbaert, 2011 e Souza, 2000. 
ERDURAN, S.; SIMON, S.; OSBORNE, J. TAPping into argumentation: developments in the application of Toulmin's argument pattern for studying science discourse. Science Education, Hoboken, v. 88, n. 6, p. 915-933, 2004.

ERDURAN, Sibel; JIMÉNEZ-ALEXANDRE, Maria Pilar. Argumentation in science education: an overview, Argumentation in Science Education: perspectives from classroom-based research / organizador por: Jiménez-Alexandre; Erduran, Sibel. Alemanha: Springer, 2007.

GLASSNER, A., WEINSTOCK, M. \& NEUMAN, Y. Pupils' evaluation and generation of evidence and explanation in argumentation. British Journal of Educational Psychology, n. 75, p. 105-118, 2005.

HAESBAERT, Rogério. O mito da desterritorialização: do "fim dos territórios" à multiterritorialidade. Rio de Janeiro: Bertrand Brasil, 2011.

JIMÉNEZ-ALEXANDRE, Maria Pilar; BROCOS, Pablo. Desafios metodológicos na pesquisa da argumentação em ensino de ciências. Revista Ensaio, v. 17, número especial, 2015.

JIMÉNEZ-ALEXANDRE. 10 Ideas claves: competências em argumentación y uso de pruebas. Barcelona (Espanha). Editoral GRAÓ, 2010.

JOHNSON,S. The art of argument, Primary Geographer, Spring, 2005.

KELLY, Gregory J.; TAKAO, Allison. Epistemic levels in argument: As analysis of university oceanography students' use of evidence in writing. In Science Education, 2002.

KOSTØ, Stein Dankert; RATCLIFFE, Mary. Social Aspects of Argumentation. In: Argumentation in Science Education: perspectives from classroom-based research I organizador por: Jiménez-Alexandre; Erduran, Sibel. Alemanha: Springer, 2007.

LIMA, Tânia Filipa Almeida da Silva. A Argumentação e a Educação em Ciências para a Cidadania: Qualidade de argumentos produzidos por alunos do $9^{\circ}$ ano sobre o Efeito Estufa. Dissertação de mestrado em Ciências da Educação. Portugal: Universidade do Minho, 2008.

MORAES, Jerusa Vilhena de. A alfabetização científica, a resolução de problemas e o exercício da cidadania: uma proposta para o ensino da Geografia. Tese (Doutorado). São Paulo: USP, Faculdade de Educação, 2010.

MORGAN, A. 'Argumentation, geography education and ICT', Geography, Summer, 2006.

PONTECORVO, Clotilde; GIRADET, Hilda. Arguing and Reasoning in Understanding Historical Topics. In: Cognition and Instruction, v.1 1, n. 3-4, 1993.

RAFFESTIN, Claude. Por uma geografia do poder. França. São Paulo: Ática, 1993.

ROBERTS, M. Geography Through Enquiry: Approaches to teaching and learning in the secondary school. Sheffield: Geographical Association, 2013.

SADLER, Troy D; ZEIDLER, Dana L. Patterns of Informal Reasoning in the Context of Socioscientific Decision-Making. Paper presented at the Annual Meeting of the Association for the Education of Teachers of Science, Nashville, USA, 2004. 
SADLER, Troy D; CHAMBERS, F. William; ZEIDLER, Dana L. Investigating the Crossroads of Socioscientific Issues, the Nature of Science, and Critical Thinking. Paper presented at the annual meeting of the national association for research in Science teaching, New Orleans, USA, 2002.

SARDÁ JORGE, Anna; SANMARTI PUIG, Neus. Enseñar a argumentar cientificamente: um reto de las classes de ciências. In: Enseñanza de las ciências, Barcelona, v. 18 , n. 3, p. 405-422, 2000 .

SASSERON, Lucia Helena. Alfabetização Científica no Ensino Fundamental: Estrutura e Indicadores deste processo em sala de aula. Tese de doutorado. São Paulo: FE-USP, 2008.

SASSERON, Lucia Helena \& CARVALHO, Ana Maria Pessoa de. Construindo argumentação na sala de aula: a presença do ciclo argumentativo, os indicadores de alfabetização científica e o padrão de Toulmin. In. Ciência e Educação, Bauru, v. 17, n.1,2011

SIMIELLI, M. E. R.. Cartografia no Ensino Fundamental e Médio. In: CARLOS, AFA. (Org.). A geografia na sala de aula. 2ed.São Paulo: Contexto, 2005, v. 1, p. 92-108.

SOUZA, Marcelo Lopes de. O território: sobre espaço e poder, autonomia e desenvolvimento. In. CASTRO, I. E.; GOMES, P. C. da C.; CORREÃ, R. L. (org.) Geografia: Conceitos e Temas. Rio de Janeiro: Bertrand Brasil, 2000.

SOUZA, Vanilton Camilo de; CASTELLAR, Sônia M.V. Erros didáticos e erros conceituais no ensino da Geografia: Retificações e mediações à construção do conhecimento. In: Bol. Goia. Geogr. (Online). Goiânia, v. 36, n. 2, p. 241-264, maio/ago. 2016.

SUNAL, Cynthia Szymanski; SUNAL, Dennis W.; TIRRI, Kirsi. Using Evidence in Scientific Reasoning: Exploring Characteristics of Middle School Students' Argumentation. Paper presented at the annual meeting of the national association for research in Science teaching, Seattle, USA, 2001.

TORRES, Haroldo G.; MARQUES, Eduardo C. Tamanho populacional das favelas paulistanas, ou os grandes números e a falência do debate sobre a metrópole. Trabalho apresentado no XIII Encontro da Associação Brasileira de Estudos Populacionais, Ouro Preto, novembro 4-8, 2002.

TOULMIN, Stephen. Os usos do argumento. São Paulo: Martins Fontes, 2001.

ZEIDLER, Dana L.; SADLER, Troy D.. The role of moral in argumentation: conscience, character, and care. IN: Argumentation in Science Education: perspectives from classroom-based research / organizador por: Jiménez-Alexandre; Erduran, Sibel. Alemanha: Springer, 2007.

\section{Anexo - Diário de um pesquisador do Instituto de Geografia}

15/06/2.014: Encontrei um estudo de um cientista da USP (Universidade de São Paulo) sobre o tamanho das favelas paulistanas e percebi a importância do debate que ele sugeria. Nesta pesquisa se verificou que existem dificuldades em medir a população de favelas em cidades como São Paulo. O cientista social observou que os 
dados do Censo Demográfico do IBGE e do Censo das Favelas, feito pela prefeitura de São Paulo, não demonstravam os mesmos resultados. Para se ter uma ideia da diferença, os dados de censos demográficos do IBGE afirmavam que a população em favelas na cidade de São Paulo nunca ultrapassou 900 mil pessoas, já o censo das favelas de 1.993, organizado pela prefeitura de São Paulo apresentava uma população de 1.901 .892 (cerca de $20 \%$ da população da cidade).

Coletei algumas informações sobre a área da Chiropita que podem explicar o porquê de tais dados.

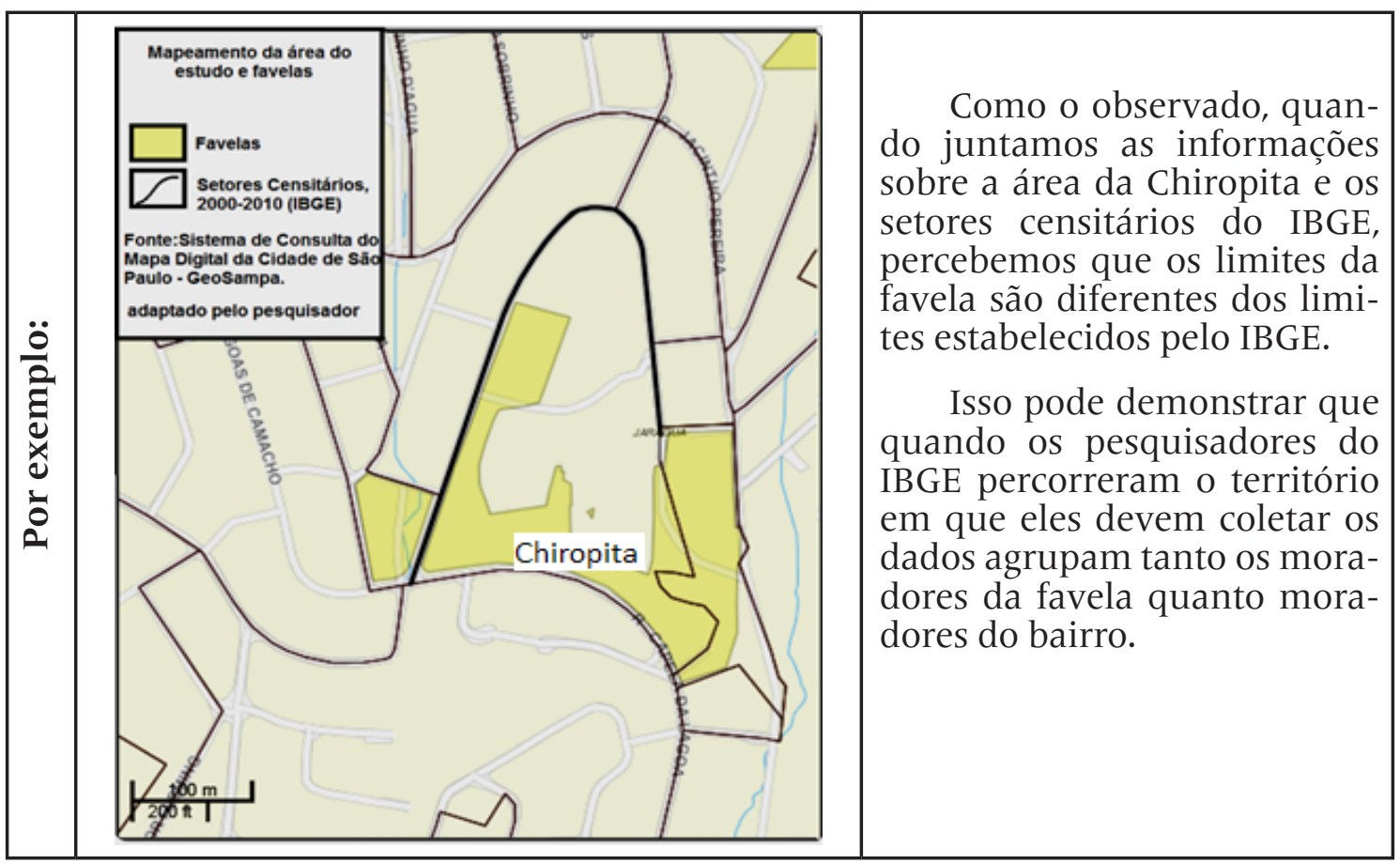

O que pretendo descobrir é se esse tipo de confusão, entre as duas instituições, se repete em outras áreas. Dependendo dos resultados poderemos saber com maior precisão que dados estão corretos e produzir outras formas de alcançar esse tipo de informações para com isso, sabermos o tamanho da situação social da população vivendo em favelas na cidade de São Paulo. A intensão é coletar mais informações selecionando como área o distrito do Jaraguá, em São Paulo.

02/11/2014: Para calcular a população de favelas no Jaraguá comparei o mapa do IBGE com o mapa de favelas da Prefeitura de São Paulo. Foram encontradas 47 favelas segundo os dados da prefeitura e 6 favelas segundo os dados do IBGE. A diferença entre os dados de população em favelas segundo o IBGE e os dados que calculei foram de $10,51 \%$. Conforme a tabela abaixo: 


\begin{tabular}{ccccc}
\hline \multicolumn{5}{c}{ Número de favelas e população favelada no distrito do Jaraguá } \\
\hline $\begin{array}{c}\text { Número de } \\
\text { favelas, Prefei- } \\
\text { tura de SP }\end{array}$ & $\begin{array}{c}\text { Número } \\
\text { de fave- } \\
\text { las, IBGE }\end{array}$ & $\begin{array}{c}\text { População, se- } \\
\text { gundo o Censo } \\
\text { do IBGE }\end{array}$ & $\begin{array}{c}\text { População Estimada } \\
\text { pela pesquisa feita }\end{array}$ & $\begin{array}{c}\text { Diferença entre os } \\
\text { dados de população } \\
\text { do IBGE e a estimada } \\
\text { pela pesquisa (\%) }\end{array}$ \\
47 & 6 & 4.689 & 5.182 & $10,51 \%$ \\
\hline
\end{tabular}

Não foi fácil calcular a população morando em favelas no Bairro do Jaraguá. Primeiro tive que comparar as áreas, nos locais em que haviam confusões entre a Prefeitura e o IBGE tive que pesquisar a densidade demográfica de cada área do IBGE (ou seja, quantos habitantes vivem e o tamanho do pedaço da área pesquisado pelo IBGE). Depois precisei medir o tamanho das áreas das favelas. Utilizei os mapas de favelas da Prefeitura e as informações do IBGE para fazer isso.

O uso do dado de densidade demográfica para mim foi importante porque com ele eu consegui saber quantos habitantes viviam e o tamanho da área em cada pedaço pesquisado pelo IBGE, por exemplo, quanto mais pessoas vivendo em uma área, maior a densidade demográfica.

Assim, eu pude com o valor da densidade demográfica multiplicar pelo tamanho da área das favelas e chegar a uma estimativa da população vivendo nestas comunidades. Chamei os dados produzidos de estimativas já que o número de pessoas vivendo muito próximas em favelas é maior do que o número de pessoas vivendo em uma mesma área comparada em bairros (...).

Em sua opinião, o pesquisador tem condições para afirmar que existem dificuldades em medir o tamanho da população residente em favelas na cidade de São Paulo? (Marque com X sua opção)

SIM NÃO

TENHO DÚVIDAS

Lembre-se de justificar sua resposta.

Objetivos: Caracterizar a qualidade com que os alunos avaliam a argumentação apresentada pelo cientista, atendendo às seguintes dimensões de análise: suficiência dos dados; relação entre os dados, garantia (fundamentação teórica), conclusão e a capacidade de refutação; identificação de limitações no estudo do cientista.No diário do pesquisador apresentam-se vários tipos de informações.

No diário do pesquisador apresentam-se vários tipos de informações. Descreva abaixo quais informações no mapa ajudaram o pesquisador a organizar a pesquisa?

Copie do diário uma informação que na tua opinião seja uma descrição dos resultados das medições.

Objetivo das questões: Averiguar se os alunos conseguem identificar Dados e Justificações num conjunto de informações facultadas apresentadas em uma tabela. 
Você acha que o estudo desenvolvido pelo pesquisador é um estudo cientifico importante? Anote abaixo qual o grau de importância que você acha que a pesquisa representa. (Marque com X sua opção)

\begin{tabular}{|l|l|l|}
\hline $\begin{array}{l}\text { A pesquisa } \\
\text { feita não é } \\
\text { importante. }\end{array}$ & $\begin{array}{l}\text { A pesquisa feita } \\
\text { é importante. }\end{array}$ & $\begin{array}{l}\text { Tenho dúvidas sobre } \\
\text { sua importância }\end{array}$ \\
\hline
\end{tabular}

Lembre-se de justificar sua resposta

Objetivos da questão: Se os estudantes consideram normas de diferentes valores: o uso de princípios morais como garantia, (e/ou) o emprego de experiências vividas e/ou considerações sobre direitos nas justificações / Caracterizar os tipos de fundamentos que foram utilizados pelos alunos na defesa de sua justificação.

(c) Copyright: Eden Correia Carli y Jerusa Vilhena de Moraes, 2018

(c) Copyright Scripta Nova, 2018.

Ficha bibliográfica:

CORREIA CARLI, Eden; VILHENA DE MORAES, Jerusa. Pratica argumentativa no ensino de geografia: um estudo a partir do conceito de território. Scripta Nova. Revista Electrónica de Geografía y Ciencias Sociales. [En línea]. Barcelona: Universidad de Barcelona, 15 de julio de 2018, vol. XXII, n 594. ISSN: 1138-9788. 